\section{Molecular \\ Syndromology}

Mol Syndromol 2018;9:30-37

DOI: $10.1159 / 000480159$
Accepted: July 7, 2017

by M. Schmid

Published online: September 13, 2017

\title{
Double Interstitial Deletion of the Long Arm of Chromosome 6 in a Patient with Pierre Robin Sequence, Dysmorphisms, and Severe Developmental Delay
}

 \\ Luigi Clauser $^{c}$ Manilo Galièc ${ }^{c}$ Alessandra Ferlini ${ }^{a}$ Sergio Fini ${ }^{a}$ \\ a UOL of Medical Genetics, and ${ }^{b}$ Neonatal Intensive Care Unit and Neonatology, Department of Reproduction and \\ Growth and Department of Medical Science, and ${ }^{\mathrm{C} C r a n i o-O r b i t o-M a x i l l o f a c i a l ~ S u r g e r y ~ U n i t, ~ U n i v e r s i t y ~ H o s p i t a l ~}$ \\ S. Anna, Ferrara, Italy
}

\section{Established Facts}

- $6 \mathrm{q}$ microdeletions involve the proximal and the distal end of the long arm of chromosome 6 .

- Several reports describe each of the 2 deletions, their size, and the associated phenotype.

\section{Novel Insights}

- Reported here is the first case of a patient with 2 simultaneous deletions in the $6 \mathrm{q}$ region. We speculate on the possible pathogenic role of some genes included in the deletions and compare our patient's clinical and dysmorphic features with those of other patients with overlapping rearrangements described in the literature.

- Our report shows how difficult it is to establish specific genotype-phenotype correlations when several pathological CNVs are simultaneously present in a patient and peculiar clinical features are absent.

\section{Keywords}

Array comparative genomic hybridization · Congenital defects $\cdot$ Microdeletion $6 q \cdot$ Psychomotor delay

\begin{abstract}
Reported here is the case of a 1.8-year-old boy with a 9.6$\mathrm{Mb}$ deletion in 6q13q14.1 and an 11.2-Mb deletion in $6 q 21 q 22.31$, ascertained through array $\mathrm{CGH}$, as the result of a complex de novo chromosome rearrangement. The clinical picture of this patient is characterized by severe psychomo-
\end{abstract}

\section{KARGER}

(๑) 2017 S. Karger AG, Basel

E-Mail karger@karger.com

www.karger.com/msy tor delay, dysmorphic features, and some congenital defects. Although, as reported in the literature, phenotypes associated with $6 q$ deletions may vary, an attempt was made to associate the patient's symptoms to either deletion, comparing them to previously reported cases. Only a limited specific correlation was found, probably due to the prevalence of very common symptoms.

(c) 2017 S. Karger AG, Basel

\section{G.P. and S.B. contributed equally to this work.}




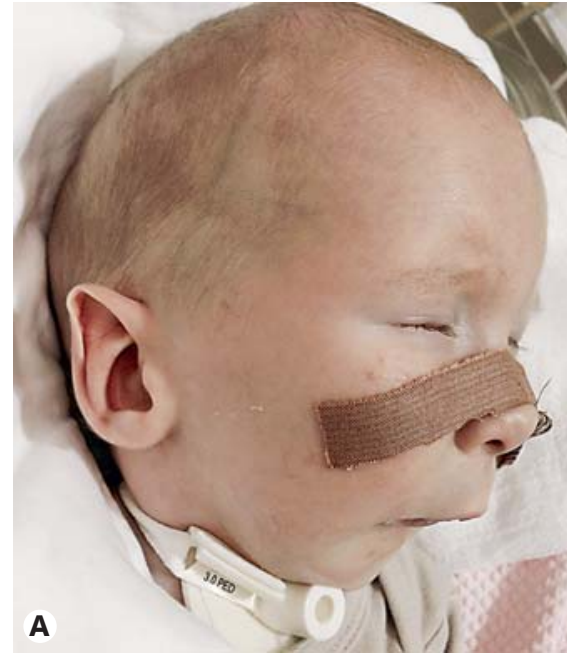

Fig. 1. Facial features of the patient at birth (A) showing hypoplastic superciliary arches, sparse eyebrows, asymmetric simple and low-set ears, long and smooth philtrum, thin upper and lower lip as well as microretrognathia. Photographs of the patient at 20 months (B-E). B Frontal view: hypoplastic superciliary arches, sparse eyebrows, upslanting palpebral fissures, bilateral epicanthus and strabismus, telecanthus, asymmetric simple and low-set ears, long and smooth philtrum, thin upper and lower lip, and microretrognathia. C Left ear: simple and low-set ear. D Hands: postaxial polydactyly (without syndactyly) of the left hand. E Feet: postaxial polydactyly (without syndactyly) of both feet.
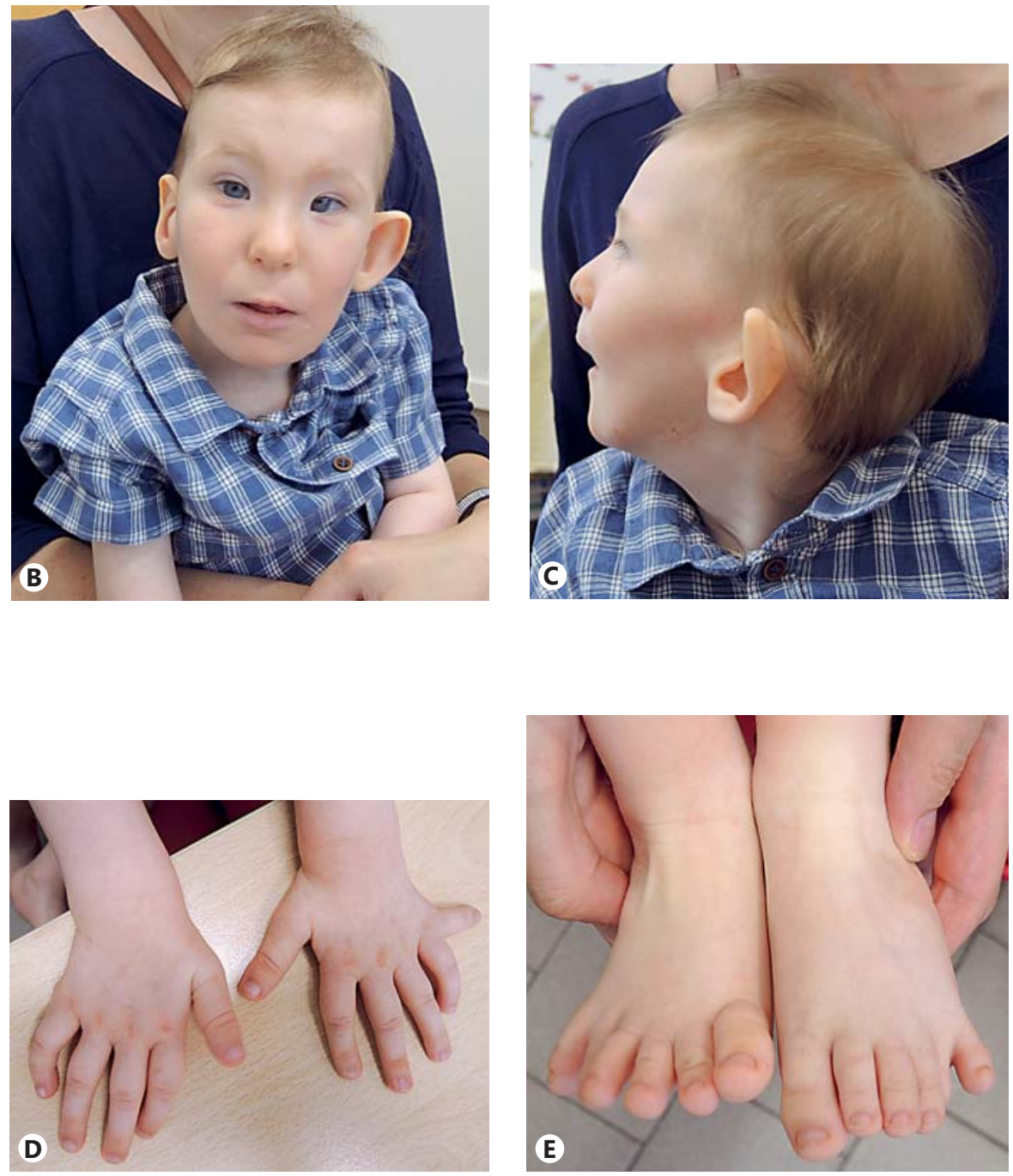

Chromosome imbalances are considered the most frequent cause of intellectual disability (ID) and/or of multiple congenital defects [Battaglia et al., 2013]. These imbalances can be due to submicroscopic deletions or duplications $(<10 \mathrm{Mb})$, and in recent years, as a result of array-CGH technique, many cases have been evidenced [Rauch et al., 2006].

A comparison between other deletions in the same submicroscopic region, described in the literature, and the knowledge of the genes involved can help to establish genotype-phenotype correlations.

We describe the case of a 1.8-year-old boy with a 9.6$\mathrm{Mb}$ deletion in 6q13q14.1 and an 11.2-Mb deletion in $6 \mathrm{q} 21 \mathrm{q} 22.31$ as the result of a complex de novo chromosome rearrangement. No other cases with this specific rearrangement are reported in the literature.

6q Deletion: Genotype-Phenotype Correlations
In order to correlate all symptoms present in the patient either to the proximal or to the distal deletion, we matched them with the data of other reported cases with comparable microdeletions.

\section{Case Report}

The proband is the first child of healthy and unrelated Romanian parents. The boy was born in Romania, at 34 weeks of gestation, by cesarean section because of breech position after an uneventful pregnancy. His family history is unremarkable. Auxological parameters at birth were normal. Multiple malformations and dysmorphic features were noticed (Pierre Robin sequence, hypertelorism, polydactyly, and dysplastic ears). Respiratory distress and cyanosis were present at birth, making oxygen therapy necessary. Tracheostomy was performed at the 17 th day of life, and a feeding tube was positioned. The echocardiogram detected a small

Mol Syndromol 2018;9:30-37

DOI: $10.1159 / 000480159$ 
ventricular septal defect, a dysplastic aortic valve, and aortic insufficiency. Transfontanellar ultrasound revealed bilateral areas of increased subependymal echogenicity, while the ventricular system and the corpus callosum were normal. Craniofacial CT showed metopic synostosis and severe mandibular hypoplasia.

At 4 months of age, the proband was therefore referred to the Cranio-Maxillofacial Surgery Unit of our hospital to undergo a specific surgical intervention for mandibular advancement by distraction osteogenesis procedure.

The dysmorphology evaluation, performed at the age of 4 months, revealed: a length of $63 \mathrm{~cm}$ (25th centile), OFC $40.2 \mathrm{~cm}$ (3rd-10th centile, i.e., relative microcephaly), and facial dysmorphisms (trigonocephaly, hypoplastic superciliary arches, sparse eyebrows, upslanting palpebral fissures, bilateral epicanthus and strabismus, telecanthus, asymmetric simple and low-set ears, long and smooth philtrum, thin upper and lower lip as well as microretrognathia). Limb anomalies consisted of postaxial polydactyly (without syndactyly) of the left hand and both feet. Micropenis and cryptorchidism were also observed (Fig. 1).

A follow-up evaluation at 20 months of age confirmed the previously described dysmorphic features. A severe psychomotor development delay was observed, and speech was characterized by only a few words. The child had generalized hypotonia and feeding difficulties because of chewing problems.

\section{Methods and Results}

Conventional chromosomal analysis ( 400 band) and FISH with chromosome-specific painting probes in peripheral lymphocytes detected 2 interstitial deletions in the long arm of chromosome 6 and 2 different translocations: a reciprocal translocation between chromosomes 1 and 4 and an insertional translocation between chromosomes 6, 1, and 15: 46,XY,der(1)t $(1 ; 4)(\mathrm{p} 31 ; \mathrm{q} 32) \operatorname{ins}(1 ; 6)$ $(\mathrm{p} 31 ; \mathrm{q}$ ?q?), der $(4) \mathrm{t}(1 ; 4)(\mathrm{p} 31 ; \mathrm{q} 32), \operatorname{del}(6)(\mathrm{q}$ ? q ?), ins $(15 ; 6)$ (q13;q?q?).ish $\operatorname{der}(1) \mathrm{t}(1 ; 4)$ ins $(1 ; 6)($ wcp $4+$,wcp6+,wcp1+), der(4) $\mathrm{t}(1 ; 4)(\mathrm{wcp} 4+, \mathrm{wcp} 1+), \operatorname{del}(6)(\mathrm{wcp} 6+)$, in s $(15 ; 6)$ (wcp15+,wcp6+,wcp15+) (Fig. 2A).

Array CGH performed using standard procedures on an $8 \times 60 \mathrm{~K}$ slide (Cytochip oligo ISCA, Blugenome LTD) with a resolution of approximately $100-250 \mathrm{~kb}$ showed 2 deletions: one in the $6 \mathrm{q} 13 \mathrm{q} 14.1$ region (from position $73,452,121$ to $83,053,393 \mathrm{bp}$ ) and the other in the $6 \mathrm{q} 21 \mathrm{q} 22.31$ region (from position $112,795,067$ to $124,005,614$ bp; hg19) (Fig. 2B, C).

The parental karyotypes were normal, indicating that the rearrangements occurred de novo.

\section{Discussion}

Using conventional cytogenetic techniques, uncommon interstitial deletions in the long arm of chromosome 6 were divided into proximal $\operatorname{del}(6)(\mathrm{q} 11 \mathrm{q} 16)$, medial $\operatorname{del}(6)(\mathrm{q} 15 \mathrm{q} 25)$, and terminal del(6)(q25qter) [Hopkin et al., 1997].

Corresponding genotype-phenotype correlations were suggested. Patients with proximal deletion q11q16 showed developmental delay, peculiar facial dysmorphic features (thin lips, upslanting palpebral fissures), microcephaly, cardiac malformation, and hernias [Hopkin et al., 1997].

Patients with medial deletions, q15q25, were usually described as having intrauterine growth retardation, abnormal respiration, upper limb malformations, and hypertelorism [Hopkin et al., 1997], while terminal deletions, q25qter, were associated with seizures, hypotonia, cleft palate, genital hypoplasia, and retinal abnormalities [Su et al., 2008; Rosenfeld et al., 2012].

The accuracy of these correlations was usually limited due to the large size of the detected deletions, partially overlapping, and the variable phenotypes.

Performing array-CGH enabled studying cases with smaller 6q deletions than the previously reported, and as a consequence, it was possible to look for more specific correlations with clinical data.

Many researchers tried to identify which genes, included in the deleted regions, would be responsible for specific features, in particular the genes with greater clinical relevance considering their function or interaction.

For example, it was suggested that deletions in SIM1 at 6q16.3 were responsible for Prader-Willi-like phenotypes [Izumi et al., 2013], while deletions in NR2E1 and SNX3 (and likely additional genes in the 6q21 region) would contribute to microcephaly [Kumar et al., 2007; Mizutani et al., 2009], and deletions of 6q21q22.31 were associated with the acro-cardio-facial syndrome phenotype [Toschi et al., 2012; Hudson et al., 2014].

However, the correlation with a specific clinical picture is not often easy and secured. Intact functioning of a large number of genes is necessary for the development of complex traits, such as intellectual and neuromotor development; therefore, different deletions of different sizes have a high probability of influencing/changing these traits.

Another complication in establishing the genotypephenotype link is that patients with completely overlapping deletions do not always present with a characteristic phenotype, even for morphological defects such as limb malformations. This was supposedly due to not completely penetrant genes, variations in other modifying genes, variations in noncoding regions, or to the effect of small RNAs or epigenetic factors, such as methylation patterns.

The 6q13q14.1-9.6-Mb region deleted in our patient includes 29 OMIM (https://www.omim.org/) genes, while 28 genes are within the 6q21q22.31-11.2-Mb-deleted region. Some of these genes have an unknown func-
32

Mol Syndromol 2018;9:30-37

DOI: $10.1159 / 000480159$
Parmeggiani/Bigoni/Buldrini/Garani/ Clauser/Galiè/Ferlini/Fini 


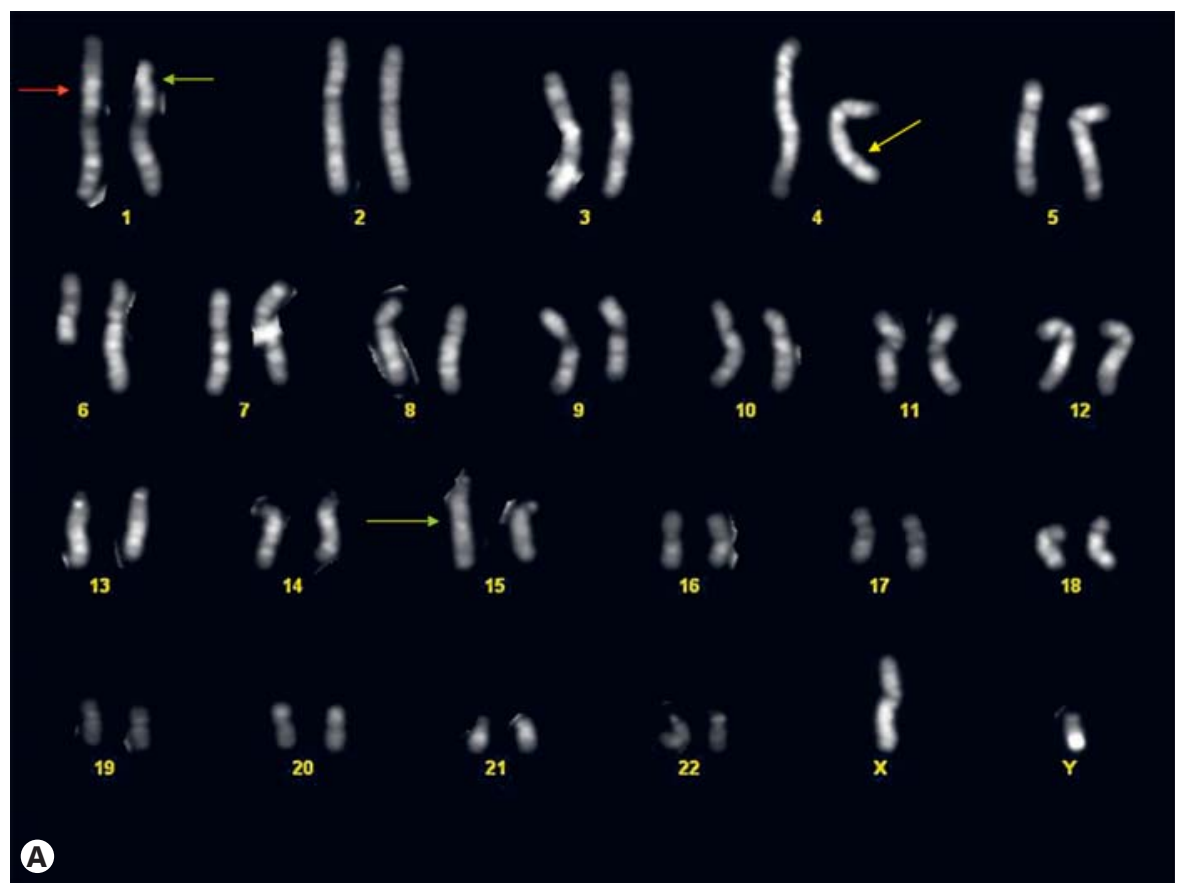

Fig. 2. A Patient's karyotype showing 2 interstitial deletions in the long arm of chromosome 6 and a reciprocal translocation between chromosomes 1 and 4 . The arrows indicate the breakpoints in the chromosomes involved in the translocation (red arrow on chromosome 1 and yellow arrow on chromosome 4). By FISH (not shown), 2 insertional translocations from chromosome 6 to chromosomes 1 and 15 were detected (green arrows indicate the insertion regions on the derivative chromosomes). B, C Array-CGH profile of chromosome 6 showing the 2 deletions in chromosome 6 as generated by CytoChip (BluGnome LTD). The breakpoint of the 6q13q14.1 deletion is from position 73,452,121 to $83,053,393 \mathrm{bp}$. The size of the deletion is about $9.6 \mathrm{Mb}$ (B). The breakpoint of the 6q21q22.31 deletion is from position $112,795,067$ to $124,005,614 \mathrm{bp}$. The size of the deletion is about $11.2 \mathrm{Mb}(\mathbf{C})$. D Schematic representation of the $6 \mathrm{q} 13 \mathrm{q} 14.1$ and the $6 \mathrm{q} 21 \mathrm{q} 22.31$ regions and of the deletions identified in our patient and in patients described in the literature. The size of the deletions, reported by the different authors, was converted, if necessary, in the hg19 assembly.

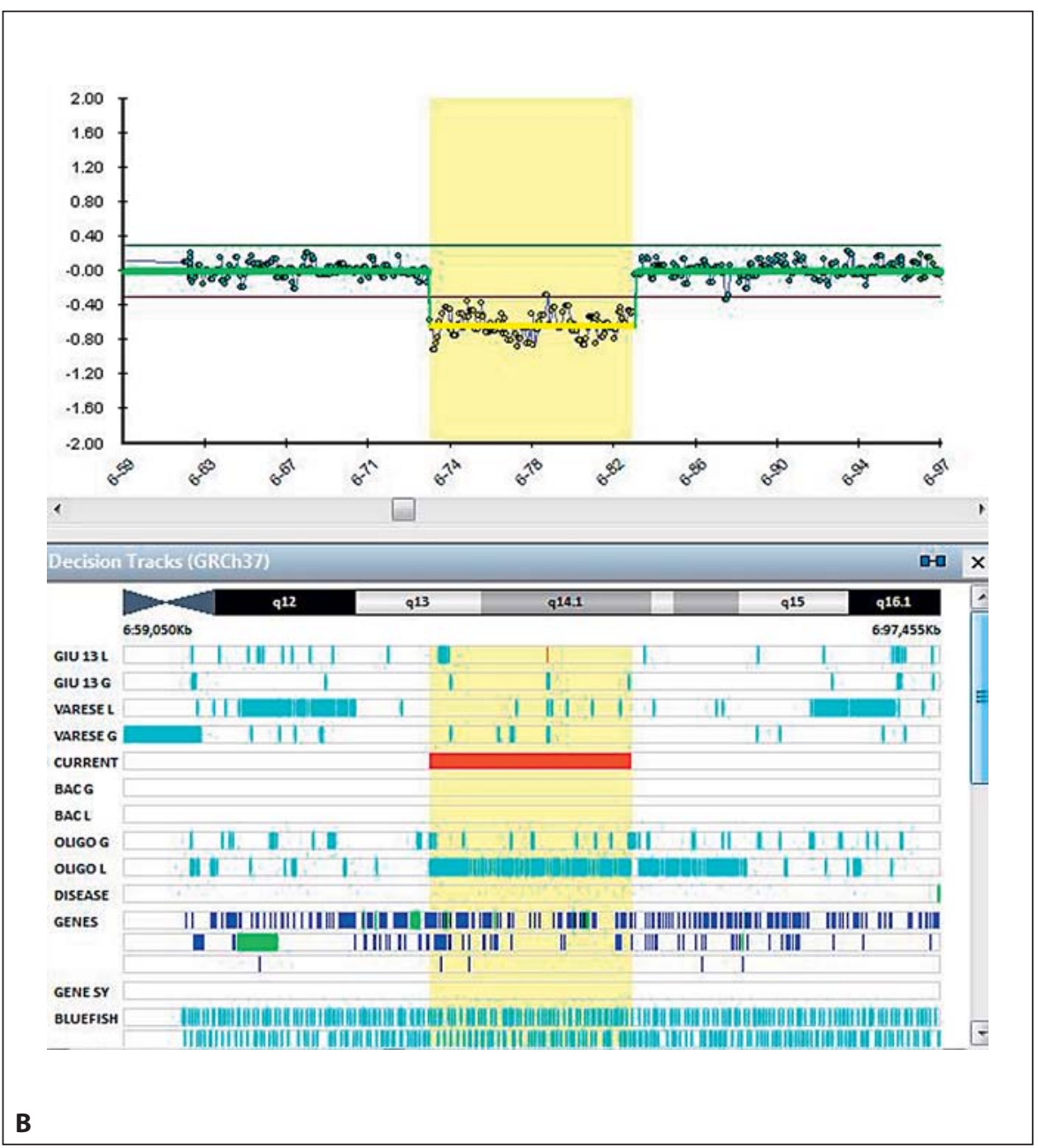

(For Figure 2C, D, see next page.)

6q Deletion: Genotype-Phenotype Correlations

Mol Syndromol 2018;9:30-37

DOI: $10.1159 / 000480159$ 

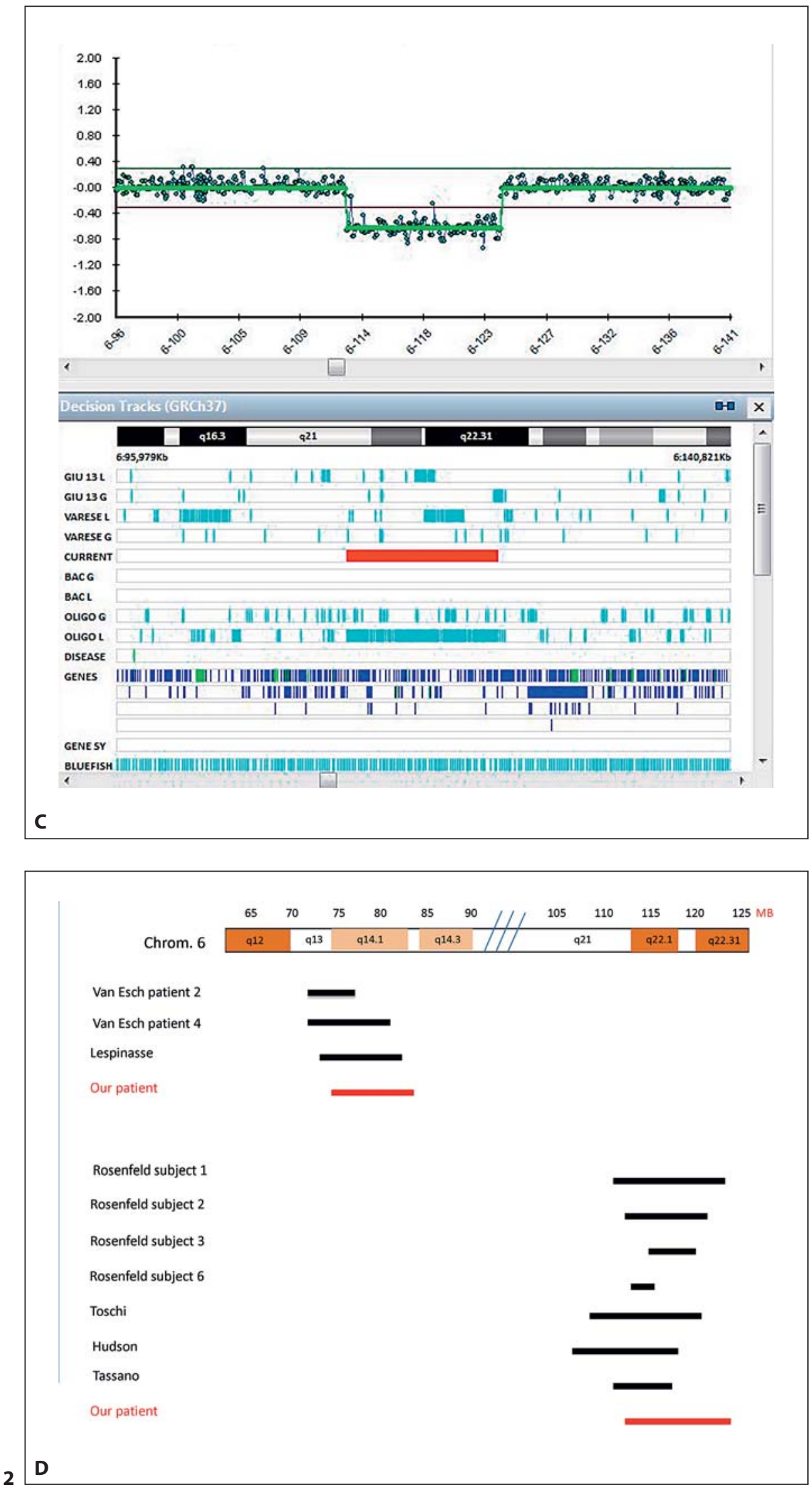
tion (e.g., SENP6 in the first CNV and CD109 in the second $\mathrm{CNV}$ ), while some others encode proteins whose function does not seem to be connected with CNS activities (e.g., the MB21D1 protein has an antiviral activity, while the NUS1 protein is important for angiogenesis). Some other deleted genes are recognized as implicated in many different clinical pictures, but these conditions are recessive (MTO1, SLC17A5, and $B C K D H B$ in proximal deletion, and DSE, RSPH4A, and RFX6 in terminal deletion).

However, a few deleted genes are dominant: metaphyseal chondrodysplasia, for example, due to COL10A1 mutations, is not a result of haploinsufficiency, and perhaps, something similar occurs for GJA1, codifying Connexin 43 , whose mutations could produce small heart septal defects and type III syndactyly. Some previous authors focused on a few genes as candidates for intellectual disability and others observed features in individuals with 6q deletions. Becker et al. [2012] hypothesized that possibly the genes responsible for intellectual disability in 6q14 may be FILIP1, MYO6, HTR1B, and SNX14. Rosenfeld et al. [2012] and Tassano et al. [2015] suggested that the deletion of MARCKS, HDAC2, and HS3ST5 in 6q21, involved in neural development, could contribute to developmental delay, behavioral changes, and other neurological abnormalities seen in patients with the deletion.

These hypotheses are very suggestive, but so far, we do not have enough evidence to support them. Even if some deleted genes are likely to play a role in the expression of the pathological symptoms in our patient, we were not able to define a causal relationship between the loss of one or more genes and the observed phenotype. We specifically looked for possible correlations between the phenotype and the proximal or distal $6 \mathrm{q}$ deletion, considering each as a compound of genes, and comparing them to those of other patients showing similar breakpoints (Fig. 2D).

The cases that could be compared to ours because of the partial overlap and size similarity with the proximal deletion 6q13q14.1 (73,452,121-83,053,393; hg19) are the Lespinasse case $(73,112,000-80,988,000$; hg17) [Lespinasse et al., 2009] and the Van Esch cases (patient 4: 72,157,311-80,953,422; hg18; patient 2: 72,654,054$76,925,922 ;$ hg18) [Van Esch et al., 2010]. A detailed comparison with the cases reported by Wentzel et al. [2010] (79,381,592-88101,121; hg18) and Lowry et al. [2013] $(80,867,031-88,301,985$; hg18) was not significant. Although they have similar extensions, the deletions are either much larger or not overlapping enough.

6q Deletion: Genotype-Phenotype Correlations
The DECIPHER database (https://decipher.sanger. ac.uk/) reports several patients with deletions of $6 q 13 q 14.1$, but only 10 have breakpoints similar to those identified in our case. These patients present mainly with delayed psychomotor development, hypotonia, facial dysmorphisms, and umbilical hernia.

Regarding the more distal 6q21q22.31 deletion, the number of cases comparable to our patient is higher. There are 4 cases described by Rosenfeld et al. [2012], 1 case by Toschi et al. [2012] (106,650,236-119,216,065; hg18), Hudson et al. [2014] (105,930,050-117,483,097; hg19), and Tassano et al. [2015] (111,884,000-116,594,000; hg19). Finally, there is the case reported by Battaglia et al. [2013] (112,781,909-121,626,897; hg19), which is not included in Fig. 2D.

The main characteristics of all cases described in the literature, and the respective deletions, are reported in Table 1 and compared to our case. Neither new symptoms were identified in our patient when compared to other cases with similar and partially overlapping deletions, nor a minimal critical region for specific phenotypes (Fig. 2D; Table 1).

Some clinical characteristics, such as psychomotor development delay and hypotonia, were present almost in all patients, either with the one or the other deletion. However, certain malformations, e.g., the particular ear morphology and perhaps the congenital cardiac defects as well as limb abnormalities, seem to be more frequently associated with the $6 \mathrm{q} 21$ deletion, resembling acro-cardio-facial syndrome. Only upslanting palpebral fissures with epicanthic folds are more common related to the $6 \mathrm{q} 14$ deletion.

However, the small number of cases available does not permit a conclusive interpretation. Moreover, the 2 deletions found in the patient reported here are part of a complex chromosome rearrangement, with at least 4 additional breakpoints. Symptoms could therefore be due to both disruptions of regulatory regions, position effects [Kleinjan and van Heyningen, 2005], and alterations of the expression patterns of dosage-sensitive genes [Bonaglia et al., 2001; Borg et al., 2005].

Nevertheless, all symptoms seen in our patient are present in the other cases reported in the literature with similar chromosome 6 microdeletions, and no additional pathological characteristic is present, confirming that these rearrangements are the main cause of the clinical picture.

In conclusion, the reported case shows how the phenotype is often uniform in many patients with different pathological CNVs. This is particularly evident when

Mol Syndromol 2018;9:30-37 DOI: $10.1159 / 000480159$ 


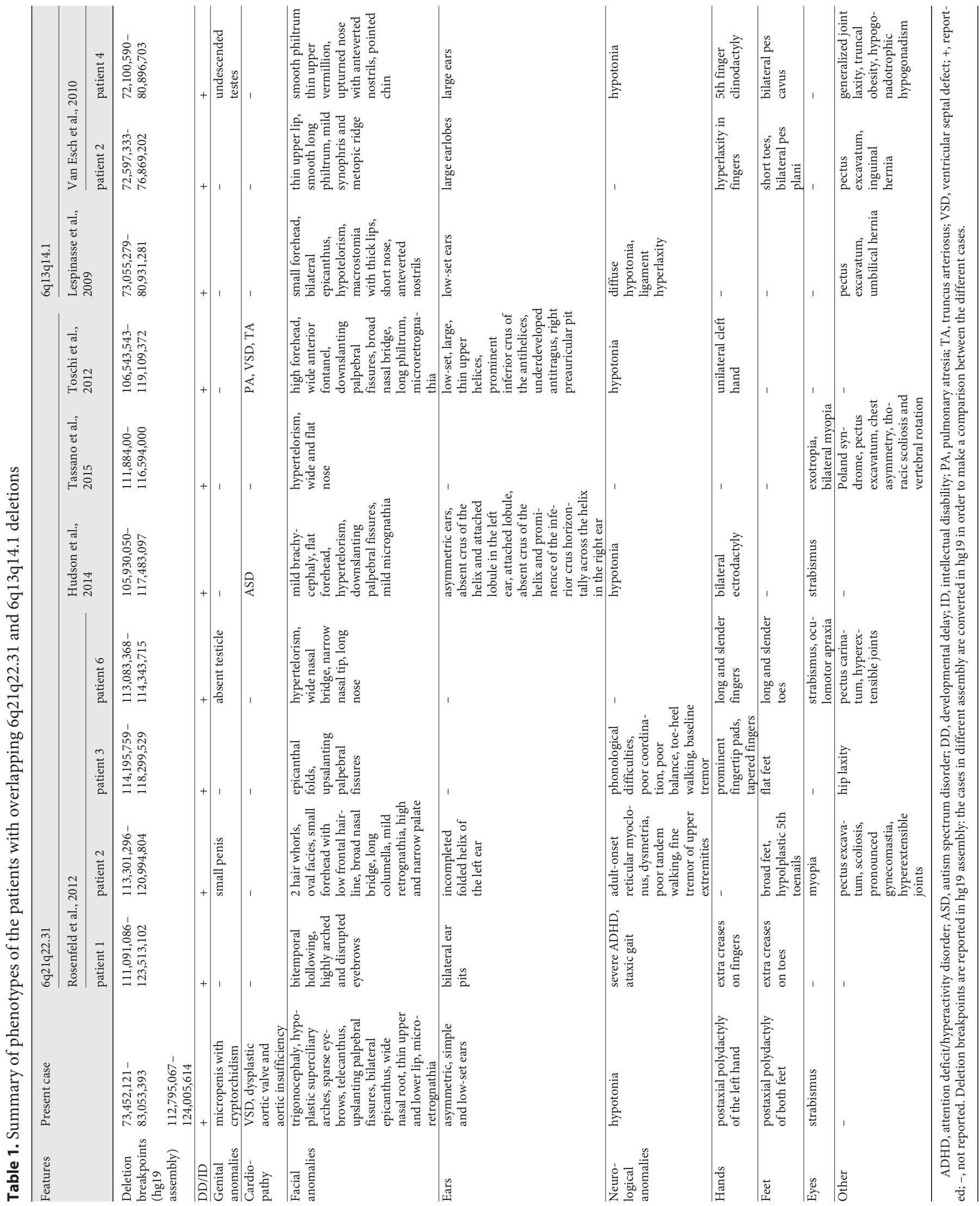


CNVs include several genes, some of which participate in networks for the establishment of complex functions, such as intellectual ability and common behavioral aspects. The simultaneous presence of more pathological CNVs in a patient, as sometimes happens, can increase the difficulty in distinguishing the respective gene contribution to the clinical picture. However, a careful clinical and dysmorphological evaluation, combined with the comparison of cases with overlapping rearrangements, may be useful to ascribe specific symptoms to the different CNVs.

\section{Acknowledgment}

We gratefully acknowledge the participation of the patient and his family.

\section{Statement of Ethics}

The authors have no ethical conflicts relevant to this manuscript to disclose. Written informed consent was obtained from the patient's parents for publication of this case report and any accompanying images.

\section{Disclosure Statement}

The authors have no conflicts of interest to declare.

\section{References}

Battaglia A, Doccini V, Bernardini L, Novelli A, Loddo A, et al: Confirmation of chromosomal microarray as a first-tier clinical diagnostic test for individuals with developmental delay, intellectual disability, autism spectrum disorders and dysmorphic features. Eur J Paediatr Neurol 17:589-599 (2013)

Becker K, Di Donato N, Holder-Espinasse M, Andrieux J, Cuisset JM, et al: De novo microdeletions of chromosome 6q14.1-q14.3 and 6q12.1-q14.1 in two patients with intellectual disability-further delineation of the $6 \mathrm{q} 14 \mathrm{mi}-$ crodeletion syndrome and review of the literature. Eur J Med Genet 55:490-497 (2012).

Bonaglia MC, Giorda R, Borgatti R, Felisari G, Gagliardi C, et al: Disruption of the ProSAP2 gene in a $\mathrm{t}(12 ; 22)(\mathrm{q} 24.1 ; \mathrm{q} 13.3)$ is associated with the 22q13.3 deletion syndrome. Am J Hum Genet 69:261-268 (2001).

Borg I, Freude K, Kübart S, Hoffmann K, Menzel C, et al: Disruption of Netrin G1 by a balanced chromosome translocation in a girl with Rett syndrome. Eur J Hum Genet 13:921-927 (2005).

Hopkin RJ, Schorry E, Bofinger M, Milatovich A, Stern HJ, et al: New insights into the phenotypes of $6 \mathrm{q}$ deletions. Am J Med Genet 70: 377-386 (1997).

Hudson C, Schwanke C, Johnson JP, Elias AF, Phillips S, et al: Confirmation of 6q21-6q22.1 deletion in acro-cardio-facial syndrome and further delineation of this contiguous gene deletion syndrome. Am J Med Genet A 164A:2109-2113 (2014).
Izumi K, Housam R, Kapadia C, Stallings VA, Medne L, et al: Endocrine phenotype of 6q16.1-q21 deletion involving SIM1 and Prader-Willi syndrome-like features. Am J Med Genet A 161A:3137-3143 (2013).

Kleinjan DA, van Heyningen V: Long-range control of gene expression: emerging mechanisms and disruption in disease. Am J Hum Genet 76:8-32 (2005).

Kumar RA, Leach S, Bonaguro R, Chen J, Yokom DW, et al: Mutation and evolutionary analyses identify NR2E1-candidate-regulatory mutations in humans with severe cortical malformations. Genes Brain Behav 6:503-516 (2007).

Lespinasse J, Gimelli S, Béna F, Antonarakis SE, Ansermet F, Paoloni-Giacobino A: Characterization of an interstitial deletion 6q13q14.1 in a female with mild mental retardation, language delay and minor dysmorphisms. Eur J Med Genet 52:49-52 (2009).

Lowry RB, Chernos JE, Connelly MS, Wyse JPH: Interstitial deletions at $6 \mathrm{q} 14.1 \mathrm{q} 15$ associate with developmental delay and marfanoid phenotype. Mol Syndromol 4:280-284 (2013).

Mizutani R, Yamauchi J, Kusakawa S, Nakamura $\mathrm{K}$, Sanbe A, et al: Sorting nexin 3, a protein upregulated by lithium, contains a novel phosphatidylinositol-binding sequence and mediates neurite outgrowth in N1E-115 cells. Cell Signal 21:1586-1594 (2009).
Rauch A, Hoyer J, Guth S, Zweier C, Kraus C, et al: Diagnostic yield of various genetic approaches in patients with unexplained developmental delay or mental retardation. Am J Med Genet A 140:2063-2074 (2006).

Rosenfeld JA, Amrom D, Andermann E, Andermann F, Veilleux M, et al: Genotype-phenotype correlation in interstitial $6 \mathrm{q}$ deletions: a report of 12 new cases. Neurogenetics 13:3147 (2012).

Su PH, Chen JY, Chen SJ, Yang KC: Terminal deletion of chromosome 6q. Pediatr Neonatol 49:88-93 (2008).

Tassano E, Mirabelli-Badenier M, Veneselli E, Puliti A, Lerone M, et al: Clinical and molecular characterization of a patient with interstitial 6q21q22.1 deletion. Mol Cytogenet 8:31 (2015).

Toschi B, Valetto A, Bertini V, Congregati C, Cantinotti M, et al: Acro-cardio-facial syndrome: a microdeletion syndrome? Am J Med Genet A 158A:1994-1999 (2012).

Van Esch H, Rosser EM, Janssens S, Van Ingelghem I, Loeys B, Menten B: Developmental delay and connective tissue disorder in four patients sharing a common microdeletion at 6q13-14. J Med Genet 47:717-720 (2010).

Wentzel C, Lynch SA, Stattin EL, Sharkey FH, Annerén G, Thuresson AC: Interstitial deletions at $6 \mathrm{q} 14.1-\mathrm{q} 15$ associated with obesity, developmental delay and a distinct clinical phenotype. Mol Syndromol 1:75-81 (2010). 6q Deletion: Genotype-Phenotype Correlations
Mol Syndromol 2018;9:30-37

DOI: $10.1159 / 000480159$ 